\title{
Collaborating with Kaspar: Using an Autonomous Humanoid Robot to Foster Cooperative Dyadic Play among Children with Autism
}

\author{
Joshua Wainer
}

Kerstin Dautenhahn

\author{
Ben Robins
}

Farshid Amirabdollahian

\begin{abstract}
This article describes a pilot study in which children with autism alternated between playing a cooperative, dyadic video game with an adult human and playing the same game with an autonomous humanoid robot. The purpose of the study was to determine whether the children, all of whom had difficulties communicating and engaging in social play with others, would display more collaborative behaviours when playing with an adult after playing and interacting with the humanoid robot. Based on our analysis of the children's behaviours while playing the cooperative game, our findings suggest that the children were more entertained, seemed more invested in the game, and collaborated better with their partners during their second sessions of playing with human adults than during their first. One possible explanation for this result is that the children's intermediary play session with the humanoid robot had an impact on their subsequent play session with the adult. Additionally, while the autistic children saw the robotic partner as being more interesting and entertaining, they played more collaboratively and cooperated better with the human adult.
\end{abstract}

\section{INTRODUCTION}

Children diagnosed with autism find human social behaviours to be difficult to interpret, complex, and occasionally random. They consequently often find it very difficult to socially interact or communicate with their peers. Additionally, not understanding how to properly interact or communicate results in these children facing many difficulties later in life [3]. Since children with autism enjoy playing with robots and other mechanical devices [20] [21], one of our laboratory's projects, Aurora, seeks to use robotic toys as therapeutic and educational aides to teach these children basic social skills that will help them to communicate and interact with others, such as turn-taking and imitation [1]. So far, the project has discovered much about how children with autism interact differently with robots than with other people, as well as how robots can successfully mediate interactions among children with autism [22] [23] [24] [31].

Research has shown that humanoid robots can stimulate dyadic imitative play with autistic children, whether the humanoids are remotely-operated robotic "puppets" or robotic toys programmed to dance to pre-recorded music [24]. Additionally, triadic interactions can be fostered among a child with autism, a humanoid robot, and a human experimenter [22]. However, it has not been shown whether playing cooperatively with humanoid robots has any effect on collaborative play skills among children with autism. This paper presents a study which examined whether having children play collaboratively with a humanoid robot affected the way the same children would play collaboratively with a typicallydeveloped adult.

\section{A. Related Work}

Autism is a lifelong developmental disability which is characterized by deficits in social interaction, impaired social communication, and restricted interests as well as stereotyped behaviours [3]. These impairments can manifest in different ways and with different degrees of severity in each person diagnosed, but they will make it difficult for those diagnosed to understand, relate to, and socially interact with other people. In children, these symptoms often manifest as displaying positive affect in social settings significantly less often than non-autistic children [8]; combining eye contact with smiling significantly less often than either neurotypical or mentally retarded children [15]; initiating joint attention using pointing (the selection and focus of gaze on the same object as someone else) far less than other children [12]; and finding it difficult to initiate and sustain social play [14]. These behaviours can be measured in order to examine the qualities of social interactions in individuals with autism [5].

Since it was first discovered that robots positively affect the social interactions of children with autism [30], many researchers have studied this phenomenon in more detail. In addition to the abovementioned projects, Fasel and others used simulated systems and robotic ones to study normal and abnormal development of joint attention in infants with and without autism [10]. Later, Kozima, Nakagawa, and others developed a simple robot, Keepon, capable of establishing triadic interactions between itself, a young child with autism, and another individual, whether another child or the autistic child's parent / caregiver [16]. Michaud and ThébergeTurmel also studied many small robotic designs (an elephant, a spherical robotic 'ball', etc) to see which one best engaged children with autism in playful interactions 
that helped them develop social skills [19].

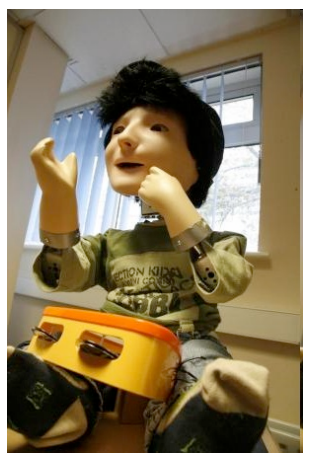

Fig. 1: Kaspar, the child-sized humanoid robot, was developed by the Adaptive Systems Research Group at the University of Hertfordshire to study human-robot interaction.

Drawing inspiration from how groups of people work together to solve problems, some human-robot interaction researchers have studied how groups of people and robots collaborate together for mutual benefit. Fong, Thorpe, and Baur found that by having humans collaborate with multiple independently-controlled robots, both were able to accomplish more than when the humans had to manually control every aspect of the robots [11]. Hinds, Roberts, and Jones studied the effects of different robot appearances and different robot status roles on the task-solving capabilities of different human-robot collaborative pairs [13]. Drury, Scholtz, and Yanco outlined an awareness framework for describing different human-robot collaboration scenarios and were able to re-evaluate different failures in a collaborative humanrobot search-and-rescue competition in terms of various deficiencies in human-robot awareness [9]. Sidner, Lee, and Lesh studied how robots could use conversational gestures and gaze patterns to better engage and sustain people in collaborative, socially assistive interactions [29].

\section{B. Research Questions and Expectations}

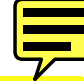

The primary goal of our research was to determine whether dyadically collaborating with a humanoid robot while playing a game would change a child with autism's collaborative dyadic interactions with a human in the same context. Previous research has shown that when used as social mediators, robots can help autistic children to interact in novel ways with other people, including other autistic children [22] [23] [24] [31]. These earlier studies compared the children's interactions in the contexts of the experiments with second-hand reports of the children's interactions in different settings, and others have focused only on single autistic children interacting dyadically with a robot or only on single children triadically interacting with their parents or carers as well as a robot. Furthermore, although it has been widely suggested that robots could be used in autism therapy settings [7] [16] [31], no study has used standardized measurements to determine whether interactin ${ }^{\mathrm{h}}$ a robot would improve a child's collaboratileractions with a particular person. We expected our study to show that after the children played with a humanoid robot, Kaspar [6] (see Figure 1), the children would play more collaboratively with their human partners than they did before playing with the robot.

TABLE I: Descriptions of the children participating in this study.

\begin{tabular}{lllll}
\hline Name & Age & Sex & $\begin{array}{l}\text { Speaking ability } \\
\text { according to } \\
\text { P-scale }\end{array}$ & $\begin{array}{l}\text { Listening ability } \\
\text { according to } \\
\text { P-scale }\end{array}$ \\
\hline D & 6 & Male & P4 & P4 \\
HT & 6 & Male & P5 & P5 \\
T & 7 & Female & P4 & P5 \\
HW & 6 & Male & P6 & P8 \\
M & 8 & Male & P4 & P4 \\
B & 6 & Male & P5 & P4 \\
\hline
\end{tabular}

\section{Participants}

Six children with autism participated in this study from Southfield School in Hatfield, a school for children with special needs; none of these children had interacted with Kaspar or played our collaborative game before. The participants consisted of five boys and one girl (see table I), and although we could not obtain the children's individual diagnoses for autism, we received confirmation from their head teacher that each child had previously been diagnosed with autism by a medical professional. Furthermore, we were given access to each child's degree of communicative competency according to the P-scale (performance scale). This is a set of performance criteria used by all schools in the UK for children with special needs working below level 1 of the UK's national curriculum. These criteria rate the children's listening and speaking skills on a scale from one (being briefly aware of interactions with familiar people) to eight (linking up to four key-words in sentences while demonstrating an understanding of causality, or listening and responding appropriately to questions regarding causality) [2]. The study took place over a period of three weeks, and all but one of the six participants played one game session per day on four days during this period; one of the children played only three video game sessions. Additionally, all the 
participants' parents signed consent forms on behalf of their children before the study began.

\section{EXPERIMENT}

\section{A. Method and Procedure}

This study was carried out with the approval of the Faculty Ethics Committee of University of Hertfordshire's faculty of Engineering and Information Science. In this study, each child played two game sessions with the same human partner, $\mathbf{H}$, and two sessions with the humanoid robot Kaspar, K. H had been trained to interact the same way with every child according to a well-rehearsed script, and $\mathbf{K}$ had been programmed to interact the same way with every child according to a specific set of inputs. Because none of the autistic children knew $\mathbf{H}$ or $\mathbf{K}$ before they played with them, each child's behaviour could not be affected by any previous experiences with them. As such, the interactions themselves became standardized and we were able to compare each child's interaction with a particular partner to those of every other child with the same partner; in contrast, had each child's human partner been a family member or friend, each child's game-playing experience could be different and would be difficult to compare with those of the other children.

We based the order in which the children would play with $\mathbf{H}$ and $\mathbf{K}$ on a method from behavi analysis known as a reversal or $\mathrm{ABAB}$ design, in which participants alternate between two experimental phases: a phase in which a baseline of behaviour is tracked for some period of time ("A", or playing with $\mathbf{H}$ ) and a phase in which an experimental intervention is implemented while the same behaviours are tracked ("B", or playing with $\mathbf{K}$ ) [28]. Each phase in our experiment consisted of a single play session on a single day, and by adding a number suffix to distinguish whether it was each child's first or second time playing the collaborative game with a human or robotic partner, we wrote the partner ordering as H1 - K1 - H2 - K2. Although the sessions lasted for up to 25 minutes, the children were free to stop playing earlier if they were bored or uncomfortable. By having every child alternate between playing partners and by using the same standardized methods for describing the collaboration in both, we were able to determine whether the children would play more collaboratively during their second play session with the human partner (H2) than during their first (H1). It important to note that having each phase consist of a single play session did not allow us to determine whether a change in a child's collaborative behaviours between $\mathrm{H1}$ and $\mathrm{H} 2$ was due to the intermediary session with Kaspar (K1) or to familiarization with $\mathbf{H}$ from repeated play sessions. However, because it allows for exploring the effects of inserting an intervention phase after a baseline (as well as a baseline after an intervention) and is a potent method when dealing with small sample sizes, the reversal design was appropriate for this study's aims.

The video game used in this experiment was designe to promote collaboration among its players; we defin "collaboration" in this study as any shared activity requiring communication, coordination, and synchronization among two or more co-located parties in order to achieve a common goal, which is a stricter definition than is generally used in research [27]. Specifically, the two players had to stand on opposite sides of a single flatbed computer monitor and communicate with each other, either verbally or by pressing buttons, to decide which of the many shapes on the screen both of them would select. Each player would then use their handheld wireless controller to move one of two orthogonal lines about on the screen, making their line intersect with the agreed-on shape. The players would then have to negotiate with each other in order to synchronize pressing the buttons on their controllers. When this was done successfully (i.e. both players selected the same shape at the same time), the players were briefly rewarded by their controllers vibrating, a pleasant sound playing from nearby speakers, and the selected shape flashing and spinning around quickly before vanishing. In addition, the child's human or robotic partner would congratulate the autistic child and praise their efforts.

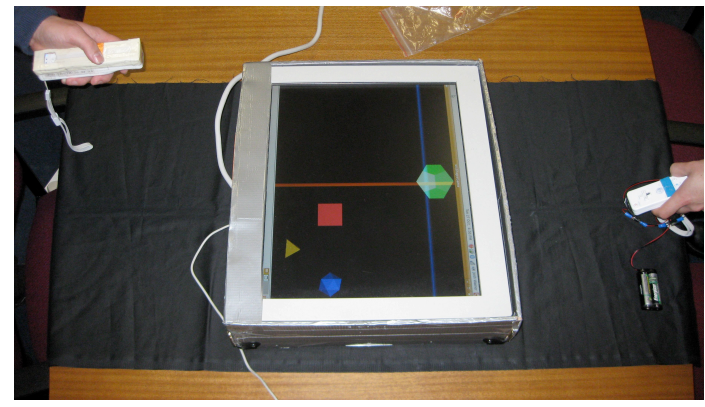

Fig. 2: The dyadic collaborative game.

The game was designed, implemented, and tested in the lab, and it incorporates certain design features for specific reasons. We decided to have the two video game players stand on opposite sides of a flatbed monitor because a horizontally-oriented screen has been found to promote greater collaborative interaction and turntaking than a vertical, upright one [26]. We allowed each player to control a line on the screen by playing with the orientation of a Nintendo Wii controller, or Wiimote, using the wiiuse v0.12 open-source libraries; one Wiimote could be rolled left and right to translate the vertical crosshair-line left and right, and the other Wiimote could be tilted up and down to translate the 


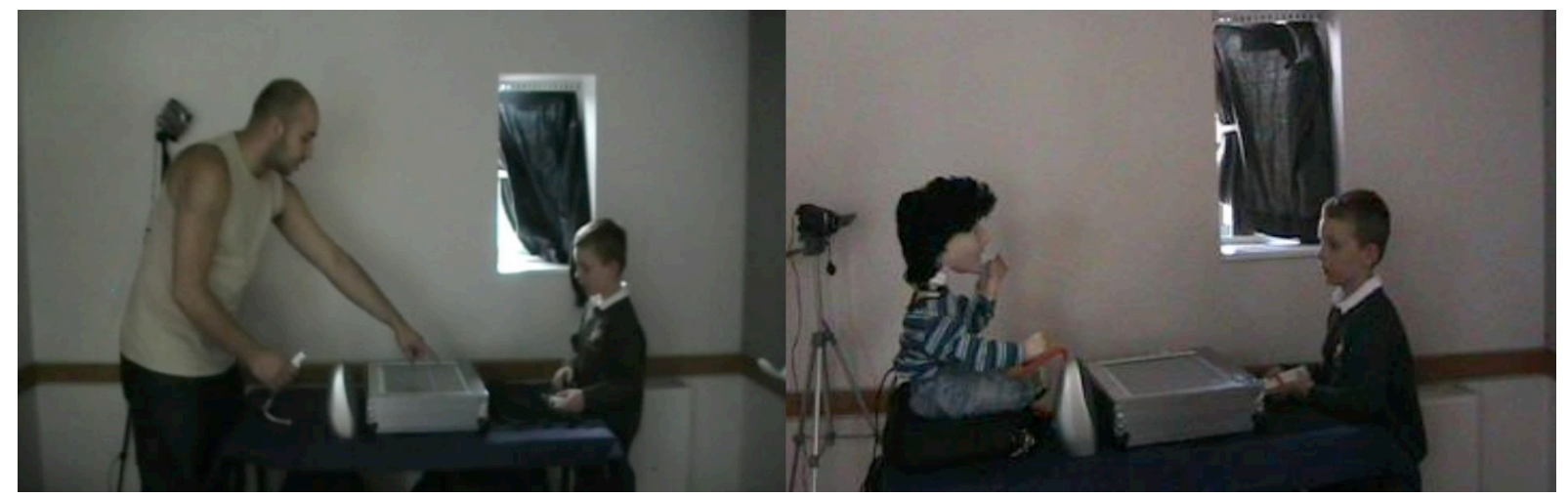

Fig. 3: Left: One of the children plays the collaborative game with $\mathbf{H}$. Right: The same child plays with $\mathbf{K}$.

horizontal crosshair-line up and down (see Figure 2). This intuitive set of controls was used to allow Kaspar to appear to play the game as easily as a human. We rendered the $3 \mathrm{D}$ graphics in the game with the OpenGL API v3.2 because it let us easily draw impressivelooking 3D shapes and change many of their visual qualities. Offering such sensory rewards served as one of the primary incentives for children with autism to participate in our games [25].

Kaspar, the humanoid robot with which the autistic children played, was designed to look like a robotic 3 -year-old boy. It is equipped with two 4 degree-offreedom (DOF) arms for waving and gesturing as well as an 8 DOF head capable of panning, tilting, blinking its eyes, and making simple facial expressions [6]. Using Yarp (Yet another robot platform) middleware, which is "a set of libraries, protocols, and tools to keep modules and devices cleanly decoupled" on a robot [18], to communicate with Kaspar's hardware, we programmed the robot to autonomously play the dyadic video game with an autistic child the same way that the human player would (see Figure 3). By constantly receiving feedback on the state of the game and the Wiimotes, Kaspar would select shapes by tilting the Wiimote strapped to its left arm, verbally prompt the children to choose a shape if they hadn't done so within a certain period of time, and occasionally choose a shape by itself. Kaspar would also respond to the buttons the children pressed (speech recognition was ruled out as a means of communication mainly due to the children's limited speech capabilities and the training required), announce when it would try to select a shape that the players' crosshair was near, and praise the children as well as smile at them when they successfully selected shapes. In short, unlike many previous HRI studies involving children with autism, our robot was not constantly controlled by a hidden human operator and did not interact with people in a "Wizard of Oz" setting.

\section{B. Data collection}

To measure how the children collaborated and interacted with their partners, whether human or robotic, we used two camcorders to videotape the children's play sessions and used the video game itself to record and timestamp both players' in-game actions. The behaviours which were manually coded from the videotapes and automatically recorded in the game's log files include:

1) prompting - a question or suggestion, verbalized by the autistic child's partner or carer, directed toward making the child choose a shape;

2) choosing - one of the players expresses their desire, verbally or through pushing a button, to select a specific shape and for the other player to move their part of the crosshair to said shape;

3) successful shape selection - the two players agreed to choose a particular shape, moved the crosshair near it, and pressed the trigger buttons on their Wiimotes simultaneously;

4) unsuccessful shape selection - the child presses the trigger button on their Wiimote when the crosshair is not near a shape, when their partner hasn't done the same, or both;

5) gaze and gaze shift - what the child looked at while playing the game, as one of the core deficits of autism is impaired gaze patterns [3]. The children's gazes were coded while looking at the game itself, the other player, the carer, the experimenter, or something in the environment unrelated to the study;

6) positive affect - the autistic child laughed or smiled while playing the game (see Figure 4).

While some of the above behaviours are inherently social activities, such as communicating one's choice to another individual, some of these behaviours are only social in the context of the collaborative game. For example, while performing a successful action in a 


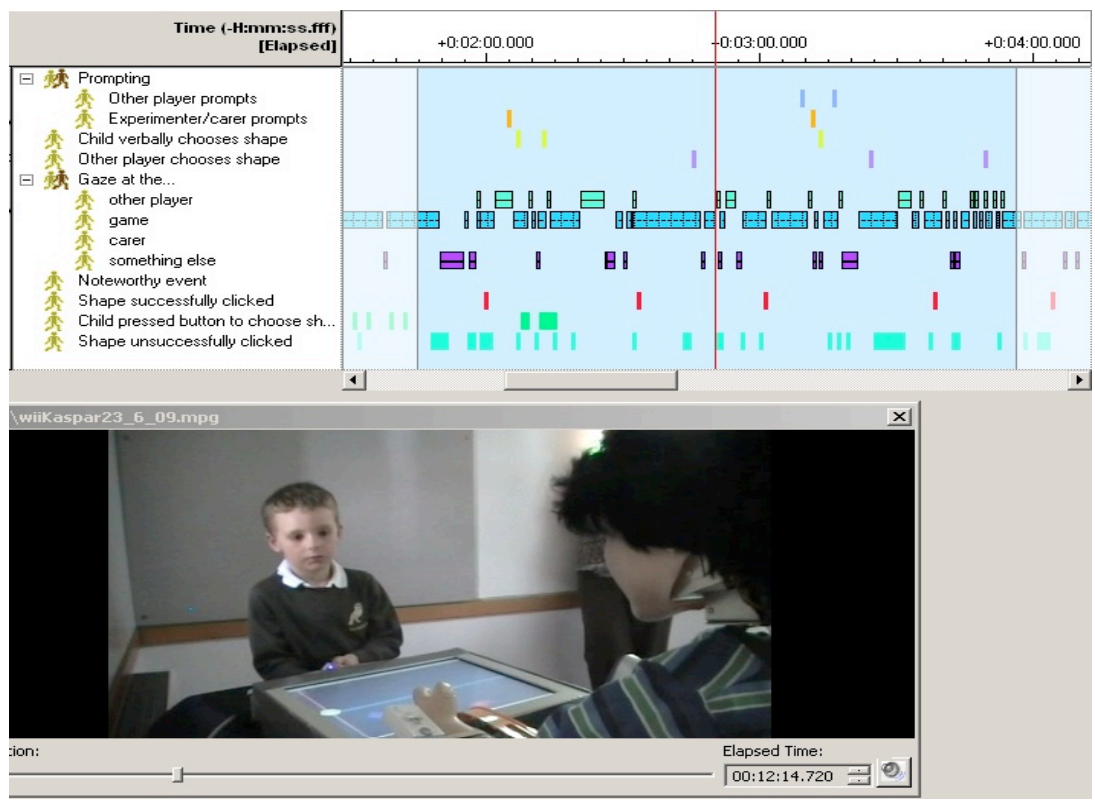

Fig. 4: An example of one child's coded behaviours represented on both a graphical timeline (top) as well as a movie player (bottom) in Noldus's Observer software package. Both the timeline's large red vertical bar and the movie player's position box represent our current position in time.

video game would not be considered inherently social, it becomes both social and cooperative in the context of this study's collaborative game since it requires two players to coordinate their actions spatially (i.e. moving each player's part of the crosshair to a specific shape) as well as temporally (i.e. synchronizing the pressing of buttons on their respective controllers) towards a common goal of selecting shapes. Furthermore, the players had to communicate with each other to coordinate how, when, and where these actions would be performed in real time. Since all of these actions are collaborative / cooperative in nature [17], the game behaviours that accomplish them are therefore also collaborative.

To ensure inter-rater reliability, the above iours were coded by the experimenter as well as second independent rater who coded $10 \%$ of the data. When the two sets of codings were analyzed for similarity, the average agreement value was 0.80 , which is generally considered to be good. We also examined the codings for reliability and received an average value for Cohen's kappa of $\kappa=0.74$. This is acceptable, as having a Cohen's kappa value higher than 0.60 suggests a good agreement between the raters [4].

\section{Analysis and Results}

Our paired sets of data had small sample sizes and abnormal distributions, so instead of using paired t-tests, we used Wilcoxon's matched pairs signed-rank tests to determine which game session pairs had statistically significant differences $(\mathrm{p}<0.05)$ regarding how often certain behaviours occurred. Additionally, we used the Mann-Whitney U test to evaluate a hypothesis regarding children having different gaze patterns and displaying positive affect while playing with different partners.

Table II shows whether there were significant differences in certain behaviour between various phases of the experiment. We expected that the children would both display positive affect more often and spend more time interacting with Kaspar than with the human player because they would want to spend more time with an enjoyable partner, so we were surprised to find that there were no significant trends regarding total time spent interacting. We also anticipated that the children would have different gaze patterns and frequencies depending on who they played with, since research has shown that for many children with autism, robots can trigger more social interaction and more interest than humans. We expected that the children would be more interested in playing the game while with Kaspar, but we were surprised that they did not also play the game more effectively while playing with it. Most importantly, we expected that playing and collaborating with Kaspar would make the children collaborate better with the human player. We describe whether our results supported our expectations in the following paragraphs.

As figure 5 shows, gaze changes regarding the game and the other player were significantly higher when playing with Kaspar. Most times (80\% of gaze switches) 
TABLE II: The results of Wilcoxon's signed rank tests comparing the children's behaviours during each play session. $\boldsymbol{X}$ - statistically insignificant, ? - marginally statistically significant, $\boldsymbol{V}$ - statistically significant

\begin{tabular}{|c|c|c|c|c|c|c|c|c|c|c|c|c|c|}
\hline & $\begin{array}{l}\text { H1 vs } \\
\mathbf{K} 1\end{array}$ & $\mathrm{H}$ & $\begin{array}{l}\mathbf{H} 2 \text { vs } \\
\mathbf{K} 2\end{array}$ & vs & $\begin{array}{l}\text { H1 vs } \\
\text { H2 }\end{array}$ & $12 \mathrm{vs}$ & & $\begin{array}{l}\mathbf{H} 1 \text { vs } \\
\mathbf{K} 1\end{array}$ & $\begin{array}{l}\text { K1 vs } \\
\mathbf{H} 2\end{array}$ & $\begin{array}{l}\mathbf{H} 2 \text { vs } \\
\mathbf{K} 2\end{array}$ & $\begin{array}{l}\text { H1 vs } \\
\mathbf{K} 2\end{array}$ & $\begin{array}{l}\text { H1 vs } \\
\text { H2 }\end{array}$ & $\begin{array}{l}\text { K1 vs } \\
\mathbf{K} 2\end{array}$ \\
\hline $\begin{array}{l}\text { e } \\
\text { rracting }\end{array}$ & $\begin{array}{l}\mathrm{Z}=-2.023 \\
\mathrm{p}=0.043 \\
\boldsymbol{V} \\
(\mathbf{H} 1<\mathbf{K} 1)\end{array}$ & $\mathbf{x}=$ & & & & 44 & & $\begin{array}{l}\mathrm{Z}=-2.201 \\
\mathrm{p}=0.028 \\
\boldsymbol{V} \\
(\mathbf{H} 1<\mathbf{K} 1)\end{array}$ & $\begin{array}{l}\mathrm{Z}=-2.201 \\
\mathrm{p}=0.028 \\
\boldsymbol{V} \\
(\mathbf{K} 1>\mathbf{H} 2)\end{array}$ & $\begin{array}{l}\mathrm{Z}=-2.023 \\
\mathrm{p}=0.043 \\
\boldsymbol{V} \\
(\mathbf{H} 2<\mathbf{K} 2)\end{array}$ & $\begin{array}{l}\mathrm{Z}=-2.023 \\
\mathrm{p}=0.043 \\
\boldsymbol{V} \\
(\mathbf{H} 1<\mathrm{K} 2)\end{array}$ & & \\
\hline total t & $\begin{array}{l}0.028 \\
<\mathbf{K} 1)\end{array}$ & 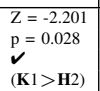 & 0.043 & $\begin{array}{l}=0.043 \\
1<\mathbf{K} 2)\end{array}$ & 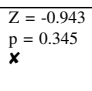 & $\begin{array}{l}674 \\
600\end{array}$ & $\begin{array}{l} \\
\text { child } \\
\text { sitive }\end{array}$ & 461 & $\begin{array}{l}\mathrm{Z}= \\
\mathrm{p}=\end{array}$ & 8 & 25 & $\begin{array}{l}\mathrm{Z}=-2.023 \\
\mathrm{p}=0.043 \\
\boldsymbol{V} \\
(\mathbf{H} 1<\mathbf{H} 2)\end{array}$ & \\
\hline $\begin{array}{l}\text { Proportion of } \\
\text { total time spent } \\
\text { gazing at game }\end{array}$ & $\begin{array}{l}-2.201 \\
0.028 \\
>\mathbf{K} 1) \\
\end{array}$ & $\begin{array}{l}\mathrm{Z}=-2.201 \\
\mathrm{p}=0.028 \\
\boldsymbol{v} \\
(\mathbf{K} 1<\mathbf{H} 2)\end{array}$ & 223 & $\begin{array}{l}023 \\
\mathbf{0 3} \\
\mathbf{K} 2) \\
\end{array}$ & & & & $\begin{array}{l}=-2.201 \\
=0.028 \\
1>\mathbf{K} 1)\end{array}$ & $\begin{array}{l}.201 \\
.028 \\
<\mathbf{H} 2) \\
\end{array}$ & $\begin{array}{l}023 \\
43 \\
\text { K2) } \\
\end{array}$ & $\begin{array}{l}\mathrm{Z}=-2.023 \\
\mathrm{p}=0.043 \\
\boldsymbol{V} \\
(\mathbf{H} 1>\mathbf{K} 2)\end{array}$ & $\begin{array}{l}Z=-1.572 \\
p=0.116 \\
x\end{array}$ & \\
\hline $\begin{array}{l}\text { total time spent } \\
\text { gazing at some- } \\
\text { thing else }\end{array}$ & $\begin{array}{l}\mathrm{Z}=-2.201 \\
\mathrm{p}=0.028 \\
\boldsymbol{V} \\
(\mathbf{H} 1<\mathbf{K} 1)\end{array}$ & $\begin{array}{l}\mathrm{Z}=-2.201 \\
\mathrm{p}=0.028 \\
\boldsymbol{V} \\
(\mathbf{K} 1>\mathbf{H} 2)\end{array}$ & $\begin{array}{l}\mathrm{Z}=-2.023 \\
\mathrm{p}=0.043 \\
\boldsymbol{V} \\
(\mathbf{H} 2<\mathbf{K} 2)\end{array}$ & $\begin{array}{l}\mathrm{Z}=-2.023 \\
\mathrm{p}=0.043 \\
\boldsymbol{v} \\
(\mathbf{H} 1<\mathbf{K} 2)\end{array}$ & & & me & $\begin{array}{l}\mathrm{Z}=-2.201 \\
\mathrm{p}=0.028 \\
\boldsymbol{V} \\
(\mathbf{H} 1>\mathbf{K} 1)\end{array}$ & $\begin{array}{l}\mathrm{Z}=-2.201 \\
\mathrm{p}=0.028 \\
\boldsymbol{V} \\
(\mathbf{K} 1<\mathbf{H} 2)\end{array}$ & $\begin{array}{l}-2.023 \\
0.043 \\
2>\mathbf{K} 2)\end{array}$ & $\begin{array}{l}\mathrm{Z}=-2.023 \\
\mathrm{p}=0.043 \\
\boldsymbol{V} \\
(\mathbf{H} 1>\mathbf{K} 2)\end{array}$ & & $\begin{array}{l}-1.214 \\
0.225\end{array}$ \\
\hline $\begin{array}{l}\text { Avg \# of gaze } \\
\text { changes per } \\
\text { minute }\end{array}$ & $\begin{array}{l}\mathrm{Z}=-2.201 \\
\mathrm{p}=0.028 \\
\boldsymbol{V} \\
(\mathbf{H} 1<\mathbf{K} 1)\end{array}$ & $\begin{array}{l}\mathrm{Z}=-2.201 \\
\mathrm{p}=0.028 \\
\boldsymbol{V} \\
(\mathbf{K} 1>\mathbf{H} 2)\end{array}$ & $\begin{array}{l}\mathrm{Z}=-2.023 \\
\mathrm{p}=0.043 \\
\boldsymbol{V} \\
(\mathbf{H} 2<\mathbf{K} 2)\end{array}$ & $\begin{array}{l}\mathrm{Z}=-2.023 \\
\mathrm{p}=0.043 \\
\boldsymbol{V} \\
(\mathbf{H} 1<\mathbf{K} 2)\end{array}$ & $\mathrm{p}=0.028$ & $=0.686$ & $\begin{array}{l}\text { apes } \\
\text { se per } \\
\text { e } \\
\text { her }\end{array}$ & $\begin{array}{l}Z=-1.153 \\
p=0.249 \\
x\end{array}$ & $\begin{array}{l}\mathrm{Z}=-0.105 \\
\mathrm{p}=0.917 \\
\boldsymbol{x}\end{array}$ & $\begin{array}{l}Z=-0.674 \\
p=0.500 \\
x\end{array}$ & $\begin{array}{l}Z=-0.405 \\
p=0.686 \\
x\end{array}$ & $\begin{array}{l}Z=-0.734 \\
p=0.463 \\
x\end{array}$ & $\begin{array}{l}Z=-0.944 \\
p=0.345 \\
x\end{array}$ \\
\hline $\begin{array}{l}\text { Avg \# of gaze } \\
\text { changes from/to } \\
\text { game per minute }\end{array}$ & $\begin{array}{l}\mathrm{Z}=-2.201 \\
\mathrm{p}=0.028 \\
\boldsymbol{V} \\
(\mathbf{H} 1<\mathbf{K} 1)\end{array}$ & $\begin{array}{l}\mathrm{Z}=-2.201 \\
\mathrm{p}=0.028 \\
\boldsymbol{v} \\
(\mathbf{K} 1>\mathbf{H} 2)\end{array}$ & $\begin{array}{l}\mathrm{Z}=-2.023 \\
\mathrm{p}=0.043 \\
\boldsymbol{v}\end{array}$ & $\begin{array}{l}\mathrm{Z}=-2.023 \\
\mathrm{p}=0.043 \\
\boldsymbol{V} \\
(\mathbf{H} 1<\mathbf{K} 2)\end{array}$ & $\begin{array}{l}\mathrm{Z}=-2.201 \\
\mathrm{p}=0.028 \\
\boldsymbol{V} \\
(\mathbf{H} 1<\mathbf{H} 2)\end{array}$ & $\begin{array}{l}=-0.674 \\
=0.500\end{array}$ & $\begin{array}{l}\text { Avg \# of times per } \\
\text { minute children } \\
\text { took initiative in } \\
\text { choosing shape }\end{array}$ & $\begin{array}{l}\mathrm{Z}=-1.992 \\
\mathrm{p}=0.046\end{array}$ & $\begin{array}{l}\mathrm{Z}=-2.201 \\
\mathrm{p}=0.028 \\
\boldsymbol{v}\end{array}$ & $\begin{array}{l}\mathrm{Z}=-2.023 \\
\mathrm{p}=0.043 \\
\mathrm{~V}\end{array}$ & $\begin{array}{l}Z=-1.214 \\
p=0.225 \\
\boldsymbol{x}\end{array}$ & $\begin{array}{l}\mathrm{Z}=-2.201 \\
\mathrm{p}=0.028 \\
\boldsymbol{V}\end{array}$ & $\begin{array}{l}\mathrm{Z}=-1.826 \\
\mathrm{p}=0.068\end{array}$ \\
\hline $\begin{array}{l}\text { Avg \# of gaze } \\
\text { changes from/to } \\
\text { other player per } \\
\text { minute }\end{array}$ & $\begin{array}{l}\mathrm{Z}=-2.201 \\
\mathrm{p}=0.028 \\
\boldsymbol{V} \\
(\mathbf{H} 1<\mathbf{K} 1)\end{array}$ & $\begin{array}{l}\mathrm{Z}=-2.201 \\
\mathrm{p}=0.028 \\
\boldsymbol{v} \\
(\mathbf{K} 1>\mathbf{H} 2)\end{array}$ & $\begin{array}{l}\mathrm{Z}=-2.023 \\
\mathrm{p}=0.043 \\
\boldsymbol{V} \\
(\mathbf{H} 2<\mathbf{K} 2)\end{array}$ & $\begin{array}{l}\mathrm{Z}=-2.023 \\
\mathrm{p}=0.043 \\
\boldsymbol{V} \\
(\mathbf{H} 1<\mathbf{K} 2)\end{array}$ & $\begin{array}{l}Z=-1.363 \\
p=0.173 \\
x\end{array}$ & $\begin{array}{l}Z=-0.135 \\
p=0.893 \\
x\end{array}$ & $\begin{array}{l}\text { Avg \# of times per } \\
\text { minute children } \\
\text { successfully } \\
\text { selected shapes }\end{array}$ & $\begin{array}{l}\mathrm{Z}=-1.782 \\
\mathrm{p}=0.075 \\
?\end{array}$ & $\begin{array}{l}\mathrm{Z}=-2.201 \\
\mathrm{p}=0.028 \\
\boldsymbol{v} \\
(\mathbf{K} 1<\mathbf{H} 2)\end{array}$ & $\begin{array}{l}\mathrm{Z}=-2.023 \\
\mathrm{p}=0.043 \\
\boldsymbol{V} \\
(\mathbf{H} 2>\mathbf{K} 2)\end{array}$ & $\begin{array}{l}Z=-1.483 \\
p=0.138 \\
\boldsymbol{x}\end{array}$ & $\begin{array}{l}\mathrm{Z}=-2.201 \\
\mathrm{p}=0.028 \\
\boldsymbol{V} \\
(\mathbf{H} 1<\mathbf{H} 2)\end{array}$ & $\begin{array}{l}Z=-0.674 \\
p=0.500 \\
x\end{array}$ \\
\hline
\end{tabular}
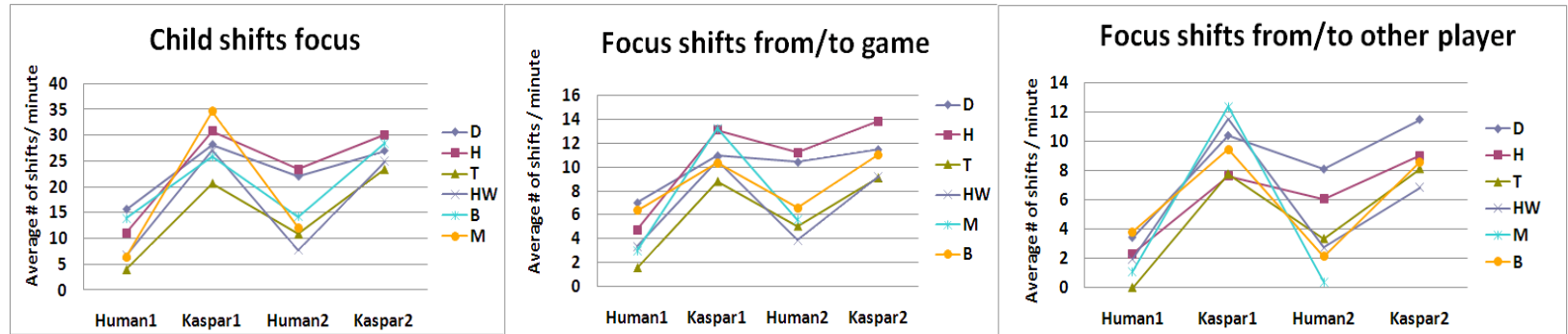

Fig. 5: The children's eye gaze shift trends.

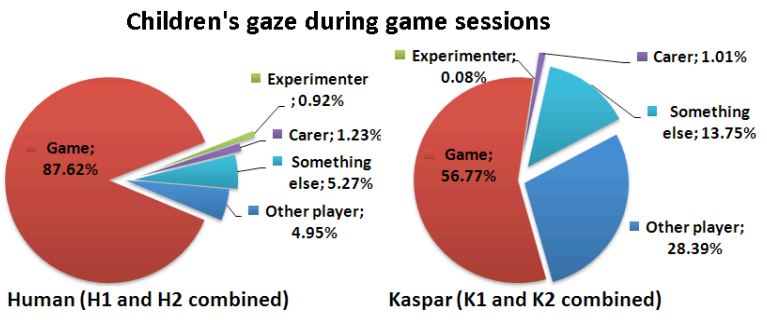

Fig. 6: The children's eye gaze while playing with either partner.

that a child looked away from the other player, the child would then look toward the game, and such focus changes between the two would occur significantly more when playing with Kaspar. In addition, we found that the children changed what they gazed at significantly more when playing with the robot, but that they also changed what they looked at more often during $\mathbf{H 2}$ than $\mathbf{H 1}$. Furthermore, the proportion of time the children spent looking at the game screen or controller ("the game") was significantly lower and the other player significantly higher when playing with Kaspar (see Figure 6).

The average number of shapes the children chose (verbally or by pressing a button on their Wiimotes) per minute was significantly lower while playing with Kaspar, and while the children chose significantly fewer shapes while looking at the game and playing with Kaspar than with a human, there was no significant difference in choosing shapes while looking at the opposite player. The children also took the initiative in choosing shapes (chose without external prompting to do so) instead of following another's lead (choosing after being prompted or selecting a shape chosen by the other player) more during $\mathbf{H} 2$ than H1. Additionally, the children successfully selected shapes through cooperating with the other player significantly more during $\mathbf{H 2}$ than H1 (see Figure 7).

The proportion of time for which the children displayed positive affect during each session did not follow any significant trends, but when we only examined the data during the sessions in which the children did exhibit 

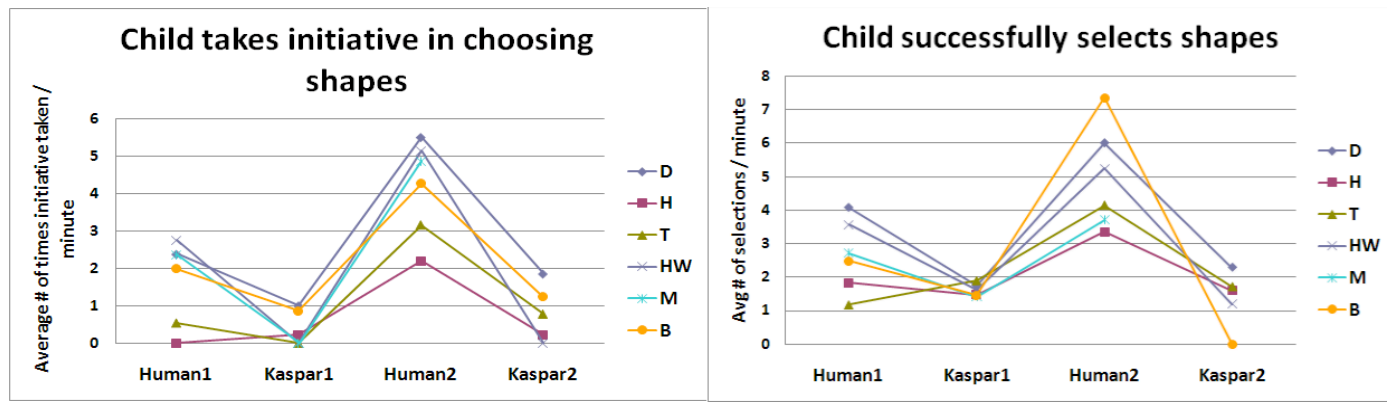

Fig. 7: The children's trends on taking the initiative in choosing shapes and cooperatively selecting them.

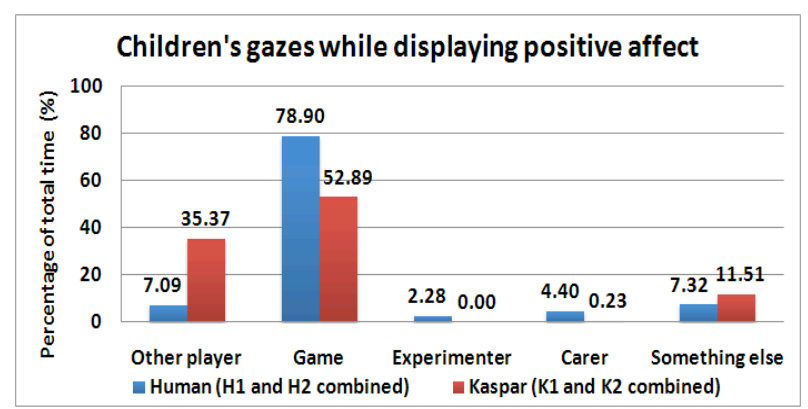

Fig. 8: The children's eye gaze trends while displaying positive affect.

positive affect, it was found that they usually looked at either the other player or the game itself. In these cases, while displaying positive affect, the proportion of time spent looking at the other player was significantly more $(\mathrm{Z}=-2.511, \mathrm{p}=0.012)$ and the game significantly less $(\mathrm{Z}=-3.24, \mathrm{p}=0.001)$ when playing with the robot (see Figure 8).

\section{Discussion}

The most noteworthy results of this study the increases in the children's actively collaborative behaviours (switching gaze focus, taking initiative in choosing shapes, and successfully selecting shapes) between the first and second sessions of playing with the human partner compared to the lack of significant changes in such behaviour between the first and second sessions of playing with Kaspar. This shows that the children only grew more interested in playing the game or more capable of collaborating when playing with the human partner, while they did not show these trends when playing with the robot. Because the two sessions of the children playing with the human partner were separated by a single session playing with Kaspar, this might mean that the children learned about collaboration through interacting with the robot and applied this knowledge to their subsequent interactions with the human player. In turn, this would support the hypothesis of this experiment as defined in section I-B. However, it is also possible that the increases in the children's actively collaborative behaviours across two play sessions with the human partner could be du to the children becoming more comfortable interactin with the human partner over time. To better investigate this issue, another study would have to be conducted that would involve sets of repeated, contiguous play sessions with both partners; interacting with robots could then be more strongly shown to improve autistic children's collaborative behaviour if findings similar to this study were only found between sets of humanpartnered play sessions which took place before and after a set of robot-partnered play sessions.

Additionally, the study shows that the children played with the human partner and Kaspar in distinctly different ways. Because the children both looked at Kaspar more and would switch their gaze between it and the game more than they would while playing with the human, we can infer that the children found Kaspar to be a more interesting game partner. In addition, the children also found Kaspar to be more fun and enjoyable than the human since when they would display positive affect, they would look more at Kaspar than at the human. However, the children did not collaborate more or better with Kaspar, as they chose more shapes and actively took the initiative instead of passively following their partner's lead more with the adult. This suggests that the children were able to perform tasks better when interacting with the human adult.

\section{CONCLUSION}

This paper presents our findings from a study in which children with autism alternated between playing a collaborative, dyadic video game with a human partner and playing the same game with a humanoid robot. The results from the study suggest that the children were more entertained, seemed more invested in the game, and collaborated better during their second sessions of playing with a human than their first, which may be due to the children's intermediary play session with the 
robotic partner. In contrast, there were no significant differences when comparing how the children played in their first and second sessions with the humanoid robot. Additionally, while the children seemed to see their robotic partner as being more interesting and more entertaining than their human partner, they seemed to solve problems collaboratively and worked together better with people.

In future studies, the following improvements to our experimental design would yield more data: a larger pool of participants for greater statistical significance, sufficient time for the children to play more than once with a given partner in each play phase, and a setup in which the robot could act as a social mediator for the children and other human partners.

\section{ACKNOWLEDGEMENTS}

The authors would like to thank our teacher contact, Sarah Nicholson, for her assistance as well as the students themselves for participating.

\section{REFERENCES}

[1] Aurora, http://www.aurora-project.com. last accessed September 17th, 2010.

[2] Pscales.com, http://www.pscales.com. last accessed May 23rd, 2010.

[3] Diagnostic and Statistical Manual of Mental Disorders, 4th edition. American Psychiatric Association, Washington DC, Washington DC, 4th edition edition, 1994.

[4] R. Bakeman and J. M. Gottman. Observing interaction : an introduction to sequential analysis. New York : Cambridge University Press, 2nd ed edition, 1997.

[5] N. Bauminger. The facilitation of social-emotional understanding and social interaction in high-functioning children with autism: Intervention outcomes. Journal of Autism and Developmental Disorders, Vol. 32:pp. 283-298, 2002.

[6] K. Dautenhahn, C. L. Nehaniv, M. Walters, B. Robins, H. KoseBagci, N. A. Mirza, and M. Blow. Kaspar - a minimally expressive humanoid robot for human-robot interaction research. Applied Bionics and Biomechanics, Special issue on "Humanoid Robots", 2009.

[7] K. Dautenhahn and I. Werry. Towards interactive robots in autism therapy: Background, motivation and challenges. Pragmatic and Cognition, 12:pp 1-35, 2004.

[8] G. Dawson, D. Hill, A. Spencer, L. Galpert, and L. Watson. Affective exchanges between young autistic children and their mothers. J Abnorm Child Psychol, 18(3):335-45, 1990.

[9] J. Drury, J. Scholtz, and H. Yanco. Awareness in human-robot interactions. In IEEE International Conference on Systems, Man and Cybernetics, pages 111-119, 2003.

[10] I. Fasel, G. Deak, J. Triesch, and J. Movellan. Combining embodied models and empirical research for understanding the development of shared attention. In Proc. of the 2nd International Conference on Development and Learning, pages pp. 21-27, 2002.

[11] T. W. Fong, C. Thorpe, and C. Baur. Collaboration, dialogue and human-robot interaction. In Proceedings of 10th International Symposium of Robotics Research, Lorne, Victoria, Australia, pages pp. 255-268, London, November 2001. Springer-Verlag.

[12] U. Frith. Autism: Explaining the Enigma. Blackwell, 1989.

[13] P. J. Hinds, T. L. Roberts, and H. Jones. Whose job is it anyway? a study of human-robot interaction in a collaborative task. Human-Computer Interaction, 19(1):151-181, 2004.
[14] R. Jordan. Social play and autistic spectrum disorders. Autism, Vol. 7(No. 4):pp 347-360, 2003.

[15] C. Kasari, M. Sigman, P. Mundy, and N. Yirmiya. Affective sharing in the context of joint attention interactions of normal, autistic, and mentally retarded children. J Autism Dev Disord, 20(1):87-100, 1990.

[16] H. Kozima, C. Nakagawa, and Y. Yasuda. Interactive robots for communication-care: A case-study in autism therapy. In Proc. of the IEEE International Workshop on Robot and Human Interactive Communication, pages pp. 341-346, 2005.

[17] T. W. Malone, T. W. Malone, K. Crowston, and K. Crowston. What is coordination theory and how can it help design cooperative work systems. In Proceedings of the Third Conference on Computer-Supported Cooperative Work, Los Angeles, Calif., Oct. 8-10, pages 357-370, New York, October 1990. ACM Press.

[18] G. Metta, P. Fitzpatrick, and L. Natale. Yarp: Yet another robot platform. International Journal on Advanced Robotics Systems, Vol. 3 (1)(No. 1):pp 43-48, 2006.

[19] F. Michaud and F. Théberge-Turmel. Mobile robotic toys and autism. In K. Dautenhahn, A. Bond, L. Canamero, and B. Edmonds, editors, Socially Intelligent Agents - Creating Relationships with Computers and Robots, pages pp. 125-132. Kluwer Academic Publishers, 2002.

[20] D. Moore. Computers and people with autism. Communication, Summer:pp 20-21, 1998.

[21] S. Powell. The use of computers in teaching people with autism. Autism on the agenda: papers from a National Autistic Society Conference, London, London, 1996.

[22] B. Robins and K. Dautenhahn. The role of the experimenter in hri research - a case study evaluation of children with autism interacting with a robotic toy. In Proc. 15th IEEE International Symposium on Robot and Human Interactive Communication, pages pp. 646-651, Piscataway, NJ, 2006. IEEE.

[23] B. Robins, K. Dautenhahn, and P. Dickerson. From isolation to communication: A case study evaluation of robot assisted play for children with autism with a minimally expressive humanoid robot. In Proc. the Second International Conferences on Advances in Computer-Human Interactions, ACHI 09, 2009.

[24] B. Robins, K. Dautenhahn, R. te Boekhorst, and A. Billard. Robotic assistants in therapy and education of children with autism: Can a small humanoid robot help encourage social interaction skills? Universal Access in the Information Society (UAIS), Vol. 4(No. 2):pp 105-120, 2005.

[25] B. Robins, N. Otero, E. Ferrari, , and K. Dautenhahn. Eliciting requirements for a robotic toy for children with autism - results from user panels. In RO-MANO7 - International Symposium on Human and Robot Communication, 2007.

[26] Y. Rogers and S. Lindley. Collaborating around vertical and horizontal large interactive displays: Which way is best? Interacting with Computers, Vol. 16:pp 1133-1152, 2004.

[27] J. Roschelle and S. Teasley. The construction of shared knowledge in collaborative problem solving. In C. OMalley, editor, Computer-supported collaborative learning, pages pp. 69-97. Springer-Verlag., New York, 1995.

[28] R. Rosenthal and R. Rosnow. Essentials of behavioral research: Methods and Data Analysis (third edition). McGraw-Hill, 2008.

[29] A. L. Sidner, C. L. Sidner, C. Lee, C. Lee, N. Lesh, and N. Lesh. Engagement rules for human-robot collaborative interactions. In Proc. IEEE International Conference on Systems, Man \& Cybernetics (CSMC), volume 4, pages 3957-3962, 2003.

[30] S. Weir and R. Emanuel. Using logo to catalyse communication in an autistic child. Technical Report DAI Research Report No. 15, University of Edinburgh, 1976.

[31] I. Werry, K. Dautenhahn, B. Ogden, and W. Harwin. Can social interaction skills be taught by a social agent? the role of a robotic mediator in autism therapy. In M. Beynon, C. L. Nehaniv, and K. Dautenhahn, editors, Proceedings of CT2001, The Fourth International Conference on Cognitive Technology: Instruments of Mind, LNAI 2117, pages pp. 57-74, 2001. 